\title{
Major comorbidities lead to the risk of adverse cardiovascular events in chronic obstructive pulmonary disease patients using inhaled long-acting bronchodilators: a case-control study
}

\author{
Yen-Fu Chen ${ }^{1,2}$, Yi-Ching Cheng ${ }^{1}$, Chien-Hong Chou ${ }^{1,2}$, Chung-Yu Chen ${ }^{1,2^{*}}$ (i) and Chong-Jen Yu ${ }^{2}$
}

\begin{abstract}
Background: While inhaled bronchodilators reduce symptoms and acute exacerbations of chronic obstructive pulmonary disease (COPD), their use is associated with increased cardiovascular events in some studies. This study investigates the risk of adverse events associated with the use of inhaled bronchodilators in COPD patients with multimorbidity.

Methods: A case-control study was conducted between January 2015 and December 2017, and patients with spirometry-confirmed diagnosis of COPD ( $N=1565)$ using inhaled long-acting bronchodilators were enrolled. Medical records were reviewed and clinical data, including age, gender, smoking status, major comorbidities, lung function stage, history of exacerbations, bronchodilator regimens, and treatment duration were analyzed. Major adverse cardiovascular events occurring during long-acting bronchodilator use were recorded.

Results: The most common comorbidities were cardiovascular disease (CVD) (53.6\%) and chronic kidney disease (CKD) (25.8\%). We observed that CVD (odds ratio [OR], 5.77), CKD (OR, 2.02) and history of frequent exacerbations $(\mathrm{OR}, 2.37)$ were independent risk factors for cardiovascular events, regardless of the type of bronchodilators use. Moreover, COPD patients with both CKD and CVD had higher risk (6.32-fold) of adverse cardiovascular effects than those with neither comorbidity. Eighty-seven of 1565 (5.56\%) COPD patients died during this study period. Of them, $21.8 \%$ (19/87) were cardiovascular-related and 73.6\% (64/87) patients were respiratory-related mortality. Among COPD patients using long-acting bronchodilators, CKD was the only risk factor to predict cardiovascular events and cardiovascular-related mortality (OR, 4.87; 95\% confidence interval [CI], 1.75-13.55].
\end{abstract}

Conclusions: COPD patients had higher risk of cardiovascular events were associated with their CVD and/or CKD comorbidities and history of frequent exacerbations, rather than associated with their use of inhaled bronchodilators.

Keywords: Cardiovascular disease, Cardiovascular events, Chronic kidney disease, Chronic obstructive pulmonary disease, Comorbidity, Long-acting bronchodilator

\footnotetext{
* Correspondence: c8101147@ms16.hinet.net

'Division of Pulmonary and Critical Care Medicine, Department of Internal

Medicine, National Taiwan University Hospital Yunlin Branch, No.579, Sec. 2,

Yunlin Rd., Douliu City, Yunlin County 640, Taiwan, Republic of China

${ }^{2}$ Division of Pulmonary and Critical Care Medicine, Department of Internal

Medicine, National Taiwan University Hospital, and College of Medicine,

National Taiwan University, Taipei, Taiwan
}

(c) The Author(s). 2019 Open Access This article is distributed under the terms of the Creative Commons Attribution 4.0 International License (http://creativecommons.org/licenses/by/4.0/), which permits unrestricted use, distribution, and

reproduction in any medium, provided you give appropriate credit to the original author(s) and the source, provide a link to the Creative Commons license, and indicate if changes were made. The Creative Commons Public Domain Dedication waiver (http://creativecommons.org/publicdomain/zero/1.0/) applies to the data made available in this article, unless otherwise stated. 


\section{Background}

Chronic obstructive pulmonary disease (COPD) is a complex respiratory disorder characterized by chronic airflow limitations and increased inflammatory responses in the airways [1]. Comorbidities are frequent in COPD and significantly affect patient's quality of life, exacerbation frequency, and survival $[1,2]$. The most prevalent comorbidities include cardiovascular disease (hypertension, ischemic heart disease, heart failure), metabolic syndrome (diabetes mellitus, hyperlipidemia), osteoporosis and chronic kidney disease (CKD) [1,3].

Inhaled bronchodilators, including long-acting $\beta 2$ agonists (LABA) and long-acting muscarinic antagonists (LAMA), and inhaled corticosteroids (ICS) are the cornerstone therapies for COPD patients [1]. The clinical efficacy of inhaled bronchodilators has been demonstrated in clinical trials as quality of life improvement, prevention of lung function decline, and reduction of acute exacerbation frequency. However, several studies have raised concerns that inhaled bronchodilators increase the risk of cardiovascular events [4-10]. Moreover, renal impairment is also a common comorbidity in elderly COPD patients $[11,12]$ who may be at higher risk of adverse events due to decreased elimination and increased systemic effects of long-acting bronchodilators [13-15]. However, in large clinical trials, COPD patients with significant renal impairment or cardiac disease were usually excluded from the studies [16-18], therefore, the safety issue of COPD patient with significant renal or cardiovascular disease using long-acting bronchodilators is still being debated [9, $10,15,16,19-21]$.

A recent analysis showed that COPD patients with CKD had high risk of pre-existing cardiovascular comorbidity [21] and they found that the safety and tolerability of dual bronchodilator is comparable to the monocomponents, irrespective of the level of renal impairment. However, the number of patients with moderate to severe renal impairment at baseline in the study remained low (less than 15\%), which may not reflect the conditions in real-life practice. Moreover, the adverse effects and the cause of mortality might not be well documented among COPD patients with major comorbidities using various inhaled medications in real-life care. Here we conducted a case-control study to investigate the association of common inhaled medications, including combining different classes of bronchodilators (LAMA and LABA) and different ICS, and the development of clinically important cardiovascular events and outcomes in COPD patients with major comorbidities.

\section{Methods}

\section{Study population}

This study enrolled COPD patients who received inhaled long-acting bronchodilators from 2015 to 2017 at National
Taiwan University Hospital (NTUH) Yunlin Branch. Eligible patients were $\geq 40$ years of age, with a clinical diagnosis of COPD verified by spirometry defined as a post-bronchodilator forced expiratory volume in 1 second $\left(\mathrm{FEV}_{1}\right) /$ forced vital capacity $(\mathrm{FVC})$ ratio $\left(\mathrm{FEV}_{1} / \mathrm{FVC}\right) \leq 0.7$ and treatment with either LAMA (tiotropium, RESPI$\mathrm{MAT}^{\odot}$ ), LABA (olodaterol RESPIMAT ${ }^{\oplus}$ ), LAMA/LABA (umeclidinium/vilanterol and glycopyrronium/indacaterol), ICS/LABA (fluticasone/salmeterol and budesonide/ formoterol) and triple therapies (ICS/LABA with tiotropium or LAMA+LABA with budesonide). Key exclusion criteria include the patients with incomplete spirometry data, clinical diagnosis of current asthma, maintenance treatment less than 30 days of continuous use or patients who inappropriately received overlapped bronchodilators (defined as patients receiving more than two bronchodilators or wrong dual or triple combinations, for example, LAMA with LABA/LAMA combination, ICS/LABA with LABA combination, ICS/LABA with other ICS combinations or two different classes of LAMA combinations... etc.) in the same period of time.

Medical records were reviewed and clinical data, including age, gender, smoking status, comorbidities, lung function stage, history of exacerbations in the previous years, bronchodilator regimens, and treatment duration were analyzed. Major adverse cardiovascular events occurring after long-acting bronchodilator inhalation and inhaled ICS were recorded.

\section{Definition of major comorbidities, cardiovascular events and outcomes}

Cardiovascular diseases (CVD) were coded from medical records and included hypertension, heart failure, coronary artery disease, and arrhythmia. Metabolic diseases included hyperlipidemia and diabetes mellitus (DM). The estimated creatinine clearance rate (Ccr) was calculated using the Cockcroft-Gault formula, and patients with an estimated $\operatorname{Ccr}<60 \mathrm{~mL} / \mathrm{min}$ for 3 or more months, with or without identifiable kidney damage were defined having chronic kidney disease [22]. Cardiovascular events included tachyarrhythmia, ischemic heart disease, decompensated heart failure, and cerebrovascular stroke. Causes of mortality including sepsis, respiratoryrelated as acute exacerbation of COPD and pneumonia, and cardiovascular-related as sudden onset of cardiac arrest, acute myocardial infarction, acute decompensated heart failure, and cerebrovascular stroke.

\section{Statistical analysis}

Baseline characteristics of COPD patients are presented as the median with the range and percentage. One-way ANOVA was used to compare the means between patients under different long-acting bronchodilators and their combined with or without inhaled ICS treatment. 
Chi-square tests with Pearson values and odds ratios for categorical variables were used to investigate the risk factors of cardiovascular effects and cerebral strokes.

The association between cardiovascular events and clinical factors including basic characteristics, underlying comorbidities, and bronchodilators use was determined using conditional logistic regression for multivariate analysis. We also compared the cardiovascular risk and cerebral strokes associated with underlying comorbidities under inhaled bronchodilators use. All statistical tests were 2-sided, with statistical significance defined as $p<0.05$. Analyses were performed using commercially available software (SPSS, version 22; IBM).

\section{Results}

\section{Clinical characteristics of COPD patients}

From the year 2015 to 2017, a total of 5130 patients were treated for COPD at National Taiwan University Hospital Yunlin Branch. Of them, 1561 patients lacked lung function spirometry data, and 813 patients were excluded for lung function with $\mathrm{FEV}_{1} / \mathrm{FVC} \geq 0.7$. Other exclusions include 98 patients with age $<40$ years old, 278 patients receiving less than 30 continuous days of bronchodilator inhalation, and 815 patients who inappropriately receiving overlapped bronchodilators. Finally, a total of 1565 COPD patients were enrolled for further analysis.

The basic characteristics of patients with spirometryconfirmed diagnosis of COPD receiving inhaled long-acting bronchodilators are shown in Table 1. The median age was 73 years, and the majority of subjects $(78.2 \%)$ were male. The major comorbidities, including hypertension (35.0\%), CKD (25.8\%), diabetes mellitus (18.0\%) and hyperlipidemia (8.4\%) were similarly distributed in each treatment cohorts. The most common inhaled therapy exposure for the COPD patients were LAMA (48.6\%), followed by ICS/LABA (35.5\%), LAMA/LABA (25.9\%), triple therapy (13.5\%) and LABA (10.3\%). Regarding inhaler switching, majority of patients $(n=1185,75.7 \%)$ exposed to only one inhaler, 254 (16.2\%) patients exposed to two kinds of inhalers (inhaler switching once), 104 (6.6\%) patients exposed to three kinds of inhalers (inhaler switching twice) and 22 (1.4\%) patients exposed to 4 kinds of inhalers (inhaler switching three times). We classified the patients into different groups (LAMA, LABA, LABA/LAMA, ICS/LABA or triple therapy) according to the inhalers they were prescribed more than 30 days and recorded the events under the inhalers use. Therefore, some patients would be reclassified to different groups after inhaler switching.

\section{Major comorbidities lead to adverse cardiovascular events}

During long-acting bronchodilator inhalation treatment, patients experienced a total of 141 cardiovascular events, including 80 ischemic heart disease attacks, 39 decompensated heart failure, 5 arrhythmia, and 17 cerebral vascular strokes. The associations of clinical characteristics with cardiovascular effects $(n=124)$ and cerebral vascular strokes $(n=17)$ in COPD patients are shown in Table 2. Our data showed that male patients (odds ratio [OR], 2.76; $p=0.001$ ), current or ever smoker (OR, 1.59; $p=$ $0.015)$, higher body mass index (BMI) ( $\geq 27$ : OR, $1.81 ; p=$ $0.002)$, poor pulmonary function $\left(\mathrm{FEV}_{1}<50 \%\right.$ : OR, 1.54 ; $p=0.025$ ), history of frequent exacerbations (exacerbation $\geq 2$ : OR, $3.59 ; p<0.001$ ) and with underlying comorbidities, including diabetes mellitus (OR, 1.90; $p=0.002)$, hyperlipidemia (OR, 2.96; $p<0.001$ ), CVD (OR, 7.76; $p<$ 0.001 ), and CKD (OR, 2.86; $p<0.001$ ) would have higher risk of adverse cardiovascular effects. The only risk factor for cerebral vascular stroke was the patients with underlying CVD (OR, 6.50, $p<0.001)$. Furthermore, COPD patients who used LAMA for long-term control had a higher risk of adverse cardiovascular effects (OR, 1.75; $p=$ 0.003). In contrast, COPD patients who treated with ICS/ LABA had a lower risk of adverse cardiovascular effects (OR, 0.64; $p=0.031$ ). The duration of treatment was not significantly associated with cardiovascular events for any of the maintenance therapies (Table 2).

In COPD patients using bronchodilators in multivariate analysis, CVD, CKD and history of frequent exacerbations were independent risk factors for cardiovascular events (Fig. 1). The increased risk of adverse cardiovascular events with LAMA use noted in univariate analysis, notably not significant in multivariate analysis. Of the comorbidities, CVD (OR, 5.77; $p<0.001$ ) and CKD (OR, 2.02; $p=0.001$ ) were the major comorbidities associated with adverse cardiovascular events in COPD patients using inhaled long-acting bronchodilators. Moreover, for COPD patients with both CKD and CVD, the risk of adverse cardiovascular events increased to 6.32-fold over that of those with neither comorbidity. In the remaining COPD patients, the risk of adverse cardiovascular events increased 1.02-fold over that of those without CKD for each $1 \mathrm{~mL} / \mathrm{min}$ decrease in renal creatinine clearance.

To further clarify the impact of major comorbidities, including cardiovascular disease and chronic kidney disease, as well as different inhaled therapies on the cardiovascular events in COPD patients, we compared the incidence and the risk of events between patient with or without major comorbidities stratified by five different inhaled bronchodilator combinations. In Table 3, the risk of cardiovascular effects was significantly higher among those with CVD or CKD than those without respectively, regardless of the type of bronchodilators for COPD patients.

\section{Chronic kidney disease predicts risk of mortality in COPD patients with multimorbidity using long- acting bronchodilators}

Eighty-seven of 1565 COPD patients died during this study period. Among them, 21.8\% patients (19 of 87 ) had 
Table 1 Characteristics of 1565 spirometry-confirmed COPD patients receiving inhaled long-acting bronchodilators

\begin{tabular}{|c|c|c|c|c|c|c|}
\hline Characteristics & All & LAMA & LABA & LAMA + LABA & $\mathrm{LABA}+\mathrm{ICS}$ & Triple therapy \\
\hline Numbers, (\%) & 1565 & $760(48.6)$ & $161(10.3)$ & $405(25.9)$ & $556(35.5)$ & $211(13.5)$ \\
\hline Age (years), median (range) & $73(40-98)$ & $73(42-96)$ & $75(43-94)$ & $73(40-93)$ & $71.5(40-98)$ & $77(42-97)$ \\
\hline \multicolumn{7}{|l|}{ Gender } \\
\hline Male & $1224(78.2)$ & $643(84.6)$ & $137(85.1)$ & $360(88.9)$ & $362(65.1)$ & $176(83.4)$ \\
\hline Female & $341(21.8)$ & $117(15.4)$ & $24(14.9)$ & $45(11.1)$ & $194(34.9)$ & 35 (16.6) \\
\hline Body mass index, median (range) & $24.2(11.0-47.5)$ & $24.1(11.2-46.2)$ & $23.5(11.2-45.5)$ & $23.8(12.0-44.1)$ & $24.5(12.0-47.5)$ & $23.2(12.8-44.2)$ \\
\hline CAT score, N(\%) & $424(27.1)$ & $240(31.6)$ & 67 (41.6) & $173(42.7)$ & $121(21.8)$ & $73(34.6)$ \\
\hline Mean (SD) & $7.74(6.35)$ & $7.44(6.39)$ & $9.67(8.02)$ & $9.41(7.21)$ & $7.06(6.12)$ & $8.85(6.04)$ \\
\hline \multicolumn{7}{|c|}{ History of exacerbations in the previous year } \\
\hline 0 & $1127(72.0)$ & $546(71.8)$ & $100(62.1)$ & $251(62.0)$ & $406(73.0)$ & $124(58.8)$ \\
\hline 1 & $316(20.2)$ & $150(19.7)$ & $37(23.0)$ & $104(25.7)$ & $111(20.0)$ & $58(27.5)$ \\
\hline$>2$ & $122(7.8)$ & $64(8.4)$ & $24(14.9)$ & $50(12.3)$ & $39(7.0)$ & $29(13.7)$ \\
\hline \multicolumn{7}{|l|}{ Smoking Status } \\
\hline Current & $266(17.0)$ & $137(18.0)$ & $30(18.6)$ & $81(20.0)$ & $80(14.4)$ & $37(17.5)$ \\
\hline Ex-smoker & $530(33.9)$ & $284(37.4)$ & $71(44.1)$ & $186(45.9)$ & $143(25.7)$ & $90(42.7)$ \\
\hline Never smoker & 769 (49.1) & $339(44.6)$ & $60(37.3)$ & $138(34.1)$ & $333(59.9)$ & $84(39.8)$ \\
\hline \multicolumn{7}{|l|}{ Spirometry $\left(\mathrm{FEV}_{1}, \%\right)$} \\
\hline$\geq 80$ & $505(32.3)$ & $315(41.4)$ & $47(29.2)$ & 75 (18.5) & $152(27.3)$ & $36(17.1)$ \\
\hline $50-79$ & $604(38.6)$ & $257(33.8)$ & $53(32.9)$ & 159 (39.3) & $249(44.8)$ & $55(26.1)$ \\
\hline $30-49$ & $360(23.0)$ & $146(19.2)$ & $45(28.0)$ & 132 (32.6) & $127(22.8)$ & $80(37.9)$ \\
\hline$\leq 29$ & $96(6.1)$ & $42(5.5)$ & $16(9.9)$ & $39(9.6)$ & $28(5.0)$ & $40(19.0)$ \\
\hline \multicolumn{7}{|l|}{ Underlying Comorbidities } \\
\hline \multicolumn{7}{|l|}{ Metabolic disease } \\
\hline Diabetes mellitus & $282(18.0)$ & $145(19.1)$ & $31(19.3)$ & $72(17.8)$ & $95(17.1)$ & $43(20.4)$ \\
\hline Hyperlipidemia & $131(8.4)$ & $77(10.1)$ & $11(6.8)$ & $41(10.1)$ & $51(9.2)$ & $12(5.7)$ \\
\hline \multicolumn{7}{|l|}{ Cardiovascular disease } \\
\hline Hypertension & $548(35.0)$ & $260(34.2)$ & $61(37.9)$ & $144(35.6)$ & $196(35.5)$ & $93(44.1)$ \\
\hline Coronary artery disease & $149(9.5)$ & $74(9.7)$ & $19(11.8)$ & 47 (11.6) & 59 (10.6) & $21(10.0)$ \\
\hline Heart failure & $93(5.9)$ & $46(6.0)$ & $12(7.5)$ & $25(6.2)$ & $34(6.1)$ & $15(7.1)$ \\
\hline Arrhythmia & $50(3.2)$ & $24(3.2)$ & $7(4.3)$ & $12(3.0)$ & $18(3.2)$ & $8(3.8)$ \\
\hline Chronic kidney disease & 360/1393 (25.8) & 178/690 (25.8) & $39 / 152(25.7)$ & 102/370 (27.6) & $114 / 479$ (23.8) & 55/197 (27.9) \\
\hline \multicolumn{7}{|l|}{ Malignancy } \\
\hline Lung cancer & $38(2.4)$ & $22(2.9)$ & $7(4.3)$ & $13(3.2)$ & $11(2.0)$ & $2(0.9)$ \\
\hline Other cancer & $27(1.7)$ & $8(1.1)$ & $2(1.2)$ & $6(1.5)$ & $9(1.6)$ & $6(2.8)$ \\
\hline
\end{tabular}

LAMA long-acting muscarinic antagonists, LABA long-acting beta2-agonists, ICS inhaled corticosteroids, SD Standard deviation, FEV ${ }_{1}$ forced expiratory volume in 1 second, CAT COPD Assessment Test

cardiovascular-related mortality and $73.6 \%$ patients $(64$ of 87) had respiratory-related mortality. The overall causes of death were listed in Table 4. Multivariate analysis showed that CKD (OR, 2.45; $p=0.001)$, CVD (OR, 1.73; $p=0.048)$ and history of frequent exacerbations (OR, 4.33; $p<0.001$ ), lung cancer (OR, 27.24; $p<0.001$ ) were independent risk factors associated with increased mortality in COPD patients using bronchodilators. However, the risk of death decreased in COPD patients with ICS/LABA use
(OR, 0.32; $p=0.001$ ) (Table 5a). Of the respiratory-related mortality, history of frequent exacerbations (OR, 4.61; $p<$ $0.001)$, lung cancer (OR, 35.79; $p<0.001)$ were the independent risk factors to increase respiratory-related mortality in COPD patients using bronchodilators (Table 5b). Of the cardiovascular-related mortality, CKD (OR, 4.87; $p=$ 0.002) was the independent risk factor to increase cardiovascular-related mortality significantly in COPD patients using bronchodilators (Table 5c). 
Table 2 The risk of cardiovascular effects and cerebral vascular strokes in COPD patients

\begin{tabular}{|c|c|c|c|c|}
\hline \multirow[t]{2}{*}{ Clinical characteristics } & \multicolumn{2}{|c|}{ Cardiovascular effects $(n=124)$} & \multicolumn{2}{|c|}{ Cerebral vascular stroke $(n=17)$} \\
\hline & Odds ratio & $P$ value & Odds ratio & $P$ value \\
\hline Male & 2.76 & $0.001^{*}$ & 0.90 & 0.861 \\
\hline Age $\geq 65 \mathrm{y} / \mathrm{o}$ & 1.52 & 0.082 & 2.41 & 0.230 \\
\hline Current or ever smoker & 1.59 & $0.015^{*}$ & 0.52 & 0.197 \\
\hline \multicolumn{5}{|l|}{ Body mass index (BMI) } \\
\hline $\mathrm{BMI}<18.5$ & 0.46 & 0.089 & 2.50 & 0.141 \\
\hline $\mathrm{BMI} \geq 27$ & 1.81 & $0.002^{*}$ & 0.60 & 0.582 \\
\hline $\mathrm{FEV}_{1}<50 \%$ & 1.54 & $0.025^{*}$ & 0.75 & 0.609 \\
\hline \multicolumn{5}{|c|}{ History of exacerbations in the previous year } \\
\hline 1 & 2.17 & $<0.001^{* *}$ & 1.42 & 3.31 \\
\hline$\geq 2$ & 3.59 & $<0.001^{* *}$ & 2.13 & 6.08 \\
\hline \multicolumn{5}{|l|}{ Major Comorbidities } \\
\hline Diabetes mellitus & 1.90 & $0.002^{*}$ & 0.28 & 0.190 \\
\hline Hyperlipidemia & 2.96 & $<0.001^{* *}$ & 1.45 & 0.619 \\
\hline Cardiovascular disease & 7.76 & $<0.001^{* *}$ & 6.50 & $0.001^{*}$ \\
\hline CKD $(\mathrm{Ccr}<60 \mathrm{ml} / \mathrm{min})$ & 2.86 & $<0.001^{* *}$ & 1.20 & 0.735 \\
\hline \multicolumn{5}{|c|}{ Bronchodilators and treatment duration } \\
\hline LAMA & 1.75 & $0.003^{*}$ & 1.52 & 0.395 \\
\hline$\geq 90$ days & 0.85 & 0.474 & 0.99 & 0.990 \\
\hline$\geq 180$ days & 0.96 & 0.866 & 0.42 & 0.134 \\
\hline$\geq 360$ days & 1.07 & 0.762 & 0.32 & 0.120 \\
\hline LABA & 1.12 & 0.702 & N/A & 0.160 \\
\hline$\geq 90$ days & 1.26 & 0.518 & N/A & 0.297 \\
\hline$\geq 180$ days & 1.54 & 0.295 & N/A & 0.404 \\
\hline$\geq 360$ days & 1.46 & 0.536 & N/A & 0.583 \\
\hline LAMA/LABA & 1.46 & 0.057 & 1.57 & 0.373 \\
\hline$\geq 90$ days & 1.01 & 0.974 & 1.96 & 0.200 \\
\hline$\geq 180$ days & 1.07 & 0.788 & 1.27 & 0.711 \\
\hline$\geq 360$ days & 1.12 & 0.727 & 2.48 & 0.144 \\
\hline ICS/LABA & 0.64 & $0.031^{*}$ & 0.39 & 0.121 \\
\hline$\geq 90$ days & 0.87 & 0.504 & 0.59 & 0.352 \\
\hline$\geq 180$ days & 0.99 & 0.953 & 0.74 & 0.601 \\
\hline$\geq 360$ days & 1.05 & 0.839 & 1.00 & 0.994 \\
\hline Triple therapy & 0.95 & 0.844 & 1.38 & 0.613 \\
\hline$\geq 90$ days & 1.02 & 0.951 & 0.59 & 0.607 \\
\hline$\geq 180$ days & 0.99 & 0.983 & 0.71 & 0.735 \\
\hline$\geq 360$ days & 0.79 & 0.588 & N/A & 0.297 \\
\hline
\end{tabular}

FEV 1 forced expiratory volume in 1 second, CKD chronic kidney disease, LAMA long-acting muscarinic antagonists, $L A B A$ long-acting beta2-agonists, ICS inhaled corticosteroids

${ }^{*} p<0.05$

${ }^{* *} p<0.001$

\section{Discussion}

Our findings demonstrated that comorbid CVD or CKD but not bronchodilator use were independent risk factors for cardiovascular events in COPD patients using long-acting inhaled bronchodilators. In COPD patients with CKD, the risk of adverse cardiovascular events increased 1.02-fold over that of patients with COPD alone for each $1 \mathrm{~mL} / \mathrm{min}$ decrease in renal creatinine clearance. In COPD patients with both CKD and CVD, this risk enhanced to 6.32-fold over that of those with 


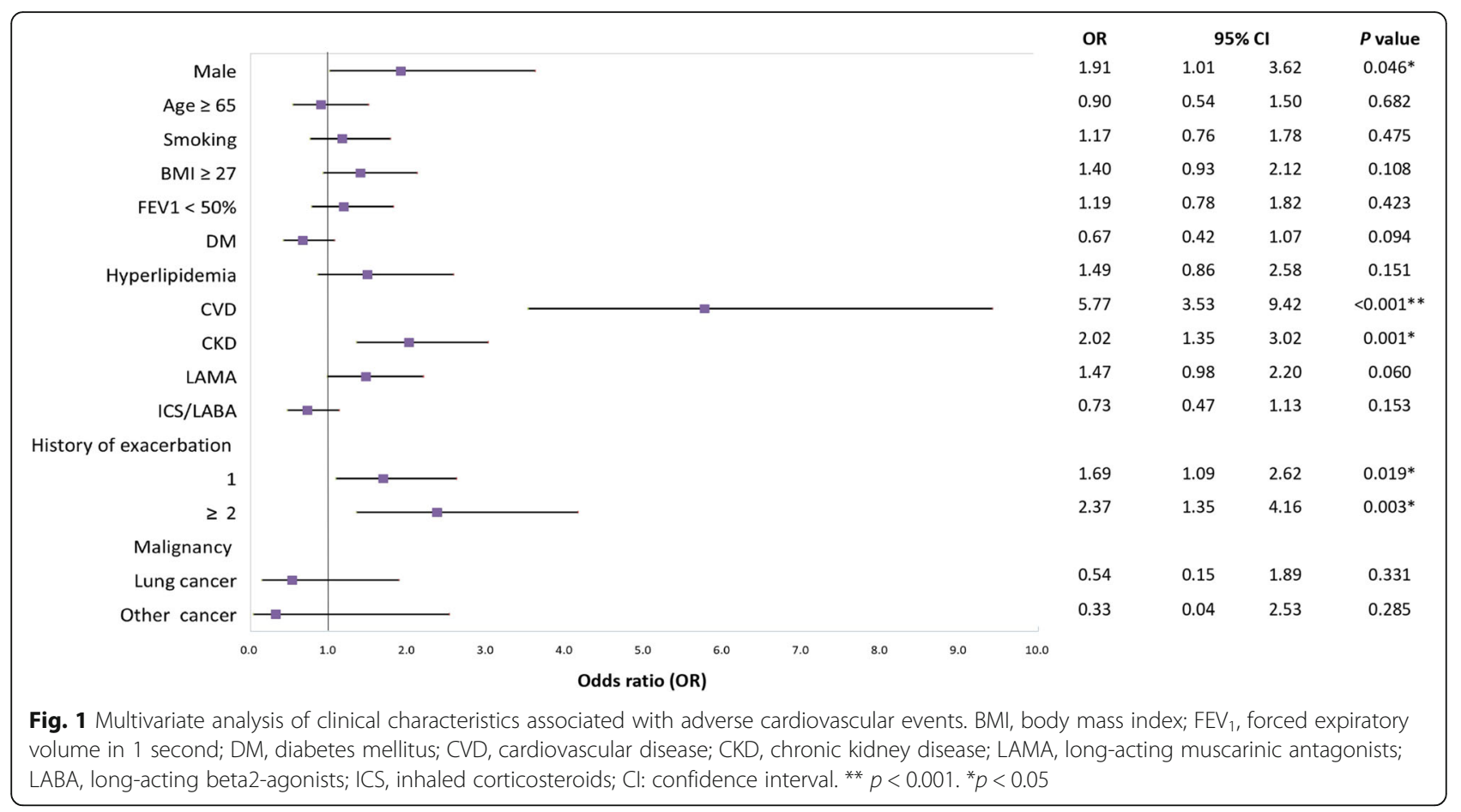

neither comorbidity, regardless of the type of inhaled long-acting bronchodilator used. Furthermore, we found that CKD was the only independent risk factor to predict cardiovascular-related mortality in COPD patients. This is the first study to raise the possibility that the increased risk of adverse cardiovascular events among COPD patients using inhaled bronchodilators results from CVD and/or CKD as their major comorbidities and history of frequent exacerbations, rather than from the use of inhaled medications themselves.

We observed that COPD patients who used LAMA had a higher risk for cardiovascular events in univariate analysis that was not statistically significant in multivariate analysis. In contrast, prior nested case-control studies by Wang et al. [9] and Gershon et al. [10] found that COPD patients newly prescribed LAMAs or LABAs were at higher risk of cardiovascular events, irrespective of prior CVD status. This discrepancy might attribute that their potential misclassification of patients with COPD by ICD codes in the National Health Insurance Research Database (without lung function confirmation) and the majority COPD patients in the cohort did not receive standard treatment (less than $15 \%$ of the patients with COPD who had cardiovascular events had been treated with long-acting bronchodilators, and the most of them used oral theophylline, beta-agonists, and an oral corticosteroid as the initial treatment) [9], which further increased cardiovascular side effects [23, 24].

Many observational studies and meta-analyses have reported that increase cardiovascular risk in patients with COPD was associated with their use of long-acting bronchodilators $[5,19,20,25,26]$, nevertheless, the randomized controlled trials failed to show an increased risk $[16,27,28]$ and a recent study even demonstrated that a LAMA/LABA combination improves cardiac function in COPD patients with lung hyperinflation [29]. This discrepancy may be partially attributable to the fact that most clinical trails have excluded patients with severe or multiple comorbidities. One population-based study indicated that the risk of cardiovascular events after initiation of long-acting bronchodilators is 3.5 -fold higher in patients with baseline CVD who are taking CVD medications [30]. Similarly, we also observed that COPD patients with baseline CVD had higher risk of cardiovascular effects than those without, regardless of treatment regimens for COPD. Further multivariate analysis demonstrated that patients with baseline CVD predicted the risk of adverse cardiovascular events. Although inhaled long-acting bronchodilators are recommended as maintenance therapy for stable COPD patients [1], clinicians should be cautious when prescribing these medications to patients with preexisting cardiovascular disease.

Recent studies showed that CKD not only has a significantly higher prevalence in COPD patients than in healthy controls [31-33], but also an important risk factor for CVD [34], which may carry high risk of cardiovascular complications [35]. The finding is of concern because LABA and LAMA are both excreted in the urine, and the systemic exposure of LABA and LAMA would be higher in COPD patients with renal impairment than those with 
Table 3 The overall incidence of cardiovascular events and stroke in COPD patients with cardiovascular disease and chronic kidney disease

\begin{tabular}{|c|c|c|c|c|c|c|}
\hline & Cardiovascular events, n (\%) & Odds ratio & $p$ & Strokes, n (\%) & Odds ratio & $p$ \\
\hline \multicolumn{7}{|l|}{ LAMA } \\
\hline With CVD $(n=317)$ & $60(18.9)$ & 6.23 & $<0.001^{* *}$ & $9(2.8)$ & 12.92 & $0.002^{*}$ \\
\hline Without $(n=443)$ & $16(3.6)$ & & & $1(0.2)$ & & \\
\hline With CKD $(n=178)$ & $36(20.2)$ & 3.08 & $<0.001^{* *}$ & $2(1.1)$ & 0.72 & 0.673 \\
\hline Without $(n=512)$ & $39(7.6)$ & & & $8(1.6)$ & & \\
\hline \multicolumn{7}{|l|}{ LABA } \\
\hline With CVD $(n=78)$ & $13(16.7)$ & 16.4 & $0.001^{*}$ & $0(0.0)$ & & \\
\hline Without $(n=83)$ & $1(1.2)$ & & & $0(0.0)$ & & \\
\hline With CKD $(n=39)$ & $7(17.9)$ & 3.34 & $0.027^{*}$ & $0(0.0)$ & & \\
\hline Without $(n=114)$ & $7(6.1)$ & & & $0(0.0)$ & & \\
\hline \multicolumn{7}{|l|}{ LABA/LAMA } \\
\hline With CVD $(n=183)$ & $33(18.0)$ & 5.89 & $<0.001^{* *}$ & $4(2.2)$ & 2.46 & 0.287 \\
\hline Without $(n=222)$ & $8(3.6)$ & & & $2(0.9)$ & & \\
\hline With CKD $(n=102)$ & $23(22.5)$ & 4.30 & $<0.001^{* *}$ & $3(2.9)$ & 2.68 & 0.215 \\
\hline Without $(n=268)$ & $17(6.3)$ & & & $3(1.1)$ & & \\
\hline \multicolumn{7}{|l|}{ ICS/LABA } \\
\hline With CVD $(n=236)$ & $30(12.7)$ & 15.39 & $<0.001^{* *}$ & $3(1.3)$ & N/A & $0.043^{*}$ \\
\hline Without $(n=320)$ & $3(0.9)$ & & & $0(0.0)$ & & \\
\hline With CKD $(n=114)$ & $17(14.9)$ & 4.09 & $<0.001^{* *}$ & $0(0.0)$ & N/A & 0.332 \\
\hline Without $(n=365)$ & $15(4.1)$ & & & $3(0.8)$ & & \\
\hline \multicolumn{7}{|l|}{ Triple therapy } \\
\hline With CVD $(n=110)$ & $13(11.8)$ & 4.38 & $0.015^{*}$ & $3(2.7)$ & N/A & 0.095 \\
\hline Without $(n=101)$ & $3(3.0)$ & & & $0(0.0)$ & & \\
\hline With CKD $(n=55)$ & $8(14.5)$ & 2.85 & $0.040^{*}$ & $1(1.8)$ & 1.30 & 0.833 \\
\hline Without $(n=142)$ & $8(5.6)$ & & & $2(1.4)$ & & \\
\hline
\end{tabular}

CVD cardiovascular disease, CKD chronic kidney disease, LAMA long-acting muscarinic antagonists, LABA long-acting beta2-agonists, ICS inhaled corticosteroids ${ }^{*} p<0.05$

** $p<0.001$

Table 4 Causes of death among COPD patients

\begin{tabular}{ll}
\hline Mortality causes & $\mathrm{N}(\%)$ \\
\hline Total & 87 \\
Cardiovascular-related & 19 \\
Cardiac arrest & $7(8.0)$ \\
Acute decompensated heart failure & $6(6.9)$ \\
Acute myocardial infarction & $3(3.4)$ \\
Cerebral vascular stroke & $3(3.4)$ \\
Respiratory-related & 64 \\
Pneumonia with respiratory failure & $38(43.7)$ \\
COPD acute exacerbation & $26(29.9)$ \\
Sepsis & 4 \\
\hline
\end{tabular}

normal renal function $[14,36]$. Thus, COPD patients with CKD receiving long-acting bronchodilators might lead to severe adverse cardiovascular effects after long-term exposure [15] and even lead to significantly higher risk of death compared to those without CKD [37-39]. Our findings documented that COPD patients comorbid CKD not only have higher risk of cardiovascular events and also predict the risk of cardiovascular-related mortality. However, this data highlights the need for further prospective studies to investigate the underlying mechanisms and potential interventions to improve outcomes in this population.

Comparative studies have failed to show a significant difference in the risk of mortality and serious adverse events between LAMA, LABA, and ICS/LABA [40, 41]. Nevertheless, a systematic review and meta-analysis demonstrated that LAMA use was associated with higher risk of overall and cardiovascular death compared with other inhaled medications and ICS/LABA use was associated 
Table 5 Multivariate analysis of clinical characteristics associated with (a) all-causes mortality, (b) respiratory-related mortality, and (c) cardiovascular-related mortality, in COPD patients

\begin{tabular}{|c|c|c|c|c|c|c|c|c|c|}
\hline & OR & $95 \% \mathrm{C}$ & & $P$ value & & OR & $95 \%$ & & $P$ value \\
\hline (a) All-causes mo & & & & & $\mathrm{BMI}>27$ & 0.85 & 0.26 & 2.79 & 0.793 \\
\hline Male & 0.79 & 0.37 & 1.67 & 0.532 & $\mathrm{FEV}_{1}<50 \%$ & 1.40 & 0.49 & 4.00 & 0.527 \\
\hline Age $\geq 65$ & 1.52 & 0.70 & 3.28 & 0.292 & $\mathrm{DM}$ & 0.49 & 0.14 & 1.71 & 0.265 \\
\hline Smoking & 0.87 & 0.50 & 1.53 & 0.634 & Hyperlipidemia & 1.14 & 0.23 & 5.70 & 0.869 \\
\hline $\mathrm{BMI} \geq 27$ & 0.53 & 0.26 & 1.07 & 0.077 & CVD & 2.99 & 0.98 & 9.10 & 0.053 \\
\hline FEV1 <50\% & 1.66 & 0.96 & 2.88 & 0.070 & CKD & 4.87 & 1.75 & 13.55 & $0.002^{*}$ \\
\hline DM & 0.70 & 0.36 & 1.37 & 0.297 & LAMA & 0.93 & 0.34 & 2.56 & 0.889 \\
\hline Hyperlipidemia & 0.58 & 0.22 & 1.58 & 0.289 & ICS/LABA & 0.33 & 0.09 & 1.25 & 0.103 \\
\hline CVD & 1.73 & 1.00 & 2.97 & $0.048^{*}$ & History of exace & רs in th & jous ye & & \\
\hline CKD & 2.45 & 1.45 & 4.14 & $0.001^{*}$ & 1 & 0.60 & 0.16 & 2.26 & 0.451 \\
\hline LAMA & 1.00 & 0.59 & 1.70 & 0.994 & $\geq 2$ & 2.01 & 0.57 & 7.12 & 0.277 \\
\hline ICS/LABA & 0.32 & 0.17 & 0.63 & $0.001^{*}$ & Malignancy & & & & \\
\hline History of exacer & ns in th & jious yea & & & Lung cancer & 1.43 & 0.17 & 12.34 & 0.742 \\
\hline 1 & 1.43 & 0.78 & 2.63 & 0.243 & Other cancer & 10.33 & 2.42 & 44.03 & $0.002^{*}$ \\
\hline $\begin{array}{c}\geq 2 \\
\text { Malignancy }\end{array}$ & 4.33 & 2.20 & 8.50 & $<0.001^{* *}$ & $\begin{array}{l}B M I \text { body mass in } \\
\text { mellitus, } C V D \text { car } \\
\text { acting muscarinic }\end{array}$ & $V_{1}$ forc & atory & $\begin{array}{l}\text { in } 1 \mathrm{sec} \\
\text { ney dise } \\
\text { 2-agonis }\end{array}$ & $\begin{array}{l}\text { M diabetes } \\
M A \text { long- } \\
\text { inhaled }\end{array}$ \\
\hline Lung cancer & 27.24 & 12.16 & 61.04 & $<0.001^{* *}$ & & & & & \\
\hline Other cancer & 19.39 & 7.85 & 47.87 & $<0.001^{* *}$ & & & & & \\
\hline
\end{tabular}

(b) Respiratory-related mortality

\begin{tabular}{|c|c|c|c|c|}
\hline & OR & \multicolumn{2}{|c|}{$95 \% \mathrm{Cl}$} & $P$ value \\
\hline \multicolumn{5}{|c|}{ (a) All-causes mortality } \\
\hline Male & 0.79 & 0.37 & 1.67 & 0.532 \\
\hline Age $\geq 65$ & 1.52 & 0.70 & 3.28 & 0.292 \\
\hline Smoking & 0.87 & 0.50 & 1.53 & 0.634 \\
\hline $\mathrm{BMI} \geq 27$ & 0.53 & 0.26 & 1.07 & 0.077 \\
\hline FEV1 $<50 \%$ & 1.66 & 0.96 & 2.88 & 0.070 \\
\hline DM & 0.70 & 0.36 & 1.37 & 0.297 \\
\hline Hyperlipidemia & 0.58 & 0.22 & 1.58 & 0.289 \\
\hline CVD & 1.73 & 1.00 & 2.97 & $0.048^{*}$ \\
\hline CKD & 2.45 & 1.45 & 4.14 & $0.001^{*}$ \\
\hline LAMA & 1.00 & 0.59 & 1.70 & 0.994 \\
\hline ICS/LABA & 0.32 & 0.17 & 0.63 & $0.001^{*}$ \\
\hline \multicolumn{5}{|c|}{ History of exacerbations in the previous year } \\
\hline 1 & 1.43 & 0.78 & 2.63 & 0.243 \\
\hline$\geq 2$ & 4.33 & 2.20 & 8.50 & $<0.001^{* *}$ \\
\hline \multicolumn{5}{|l|}{ Malignancy } \\
\hline Lung cancer & 27.24 & 12.16 & 61.04 & $<0.001^{* *}$ \\
\hline Other cancer & 19.39 & 7.85 & 47.87 & $<0.001^{* *}$ \\
\hline \multicolumn{5}{|c|}{ (b) Respiratory-related mortality } \\
\hline Male & 0.83 & 0.34 & 1.98 & 0.667 \\
\hline Age $\geq 65$ & 1.19 & 0.52 & 2.70 & 0.681 \\
\hline Smoking & 0.80 & 0.42 & 1.52 & 0.491 \\
\hline $\mathrm{BMI}>27$ & 0.48 & 0.20 & 1.15 & 0.100 \\
\hline FEV1 $<50 \%$ & 1.82 & 0.97 & 3.41 & 0.060 \\
\hline DM & 0.75 & 0.35 & 1.62 & 0.466 \\
\hline Hyperlipidemia & 0.53 & 0.16 & 1.73 & 0.295 \\
\hline CVD & 1.64 & 0.88 & 3.06 & 0.116 \\
\hline CKD & 1.52 & 0.82 & 2.82 & 0.185 \\
\hline LAMA & 1.11 & 0.61 & 2.03 & 0.739 \\
\hline ICS/LABA & 0.40 & 0.19 & 0.83 & $0.014^{*}$ \\
\hline \multicolumn{5}{|c|}{ History of exacerbations in the previous year } \\
\hline 1 & 2.03 & 1.03 & 4.00 & $0.041^{*}$ \\
\hline$\geq 2$ & 4.61 & 2.14 & 9.93 & $<0.001^{* *}$ \\
\hline \multicolumn{5}{|l|}{ Malignancy } \\
\hline Lung cancer & 35.79 & 15.65 & 81.82 & $<0.001^{* *}$ \\
\hline Other cancer & 11.72 & 4.27 & 32.17 & $<0.001^{* *}$ \\
\hline \multicolumn{5}{|c|}{ (c) Cardiovascular-related mortality } \\
\hline Male & 0.79 & 0.19 & 3.33 & 0.745 \\
\hline Age $\geq 65$ & 3.06 & 0.38 & 24.76 & 0.294 \\
\hline Smoking & 1.11 & 0.39 & 3.14 & 0.849 \\
\hline
\end{tabular}

History of exacerbations in the previous year

\begin{tabular}{|c|c|c|c|c|}
\hline & OR & \multicolumn{2}{|c|}{$95 \% \mathrm{Cl}$} & $P$ value \\
\hline \multicolumn{5}{|c|}{ (a) All-causes mortality } \\
\hline Male & 0.79 & 0.37 & 1.67 & 0.532 \\
\hline Age $\geq 65$ & 1.52 & 0.70 & 3.28 & 0.292 \\
\hline Smoking & 0.87 & 0.50 & 1.53 & 0.634 \\
\hline $\mathrm{BMI} \geq 27$ & 0.53 & 0.26 & 1.07 & 0.077 \\
\hline FEV1 $<50 \%$ & 1.66 & 0.96 & 2.88 & 0.070 \\
\hline DM & 0.70 & 0.36 & 1.37 & 0.297 \\
\hline Hyperlipidemia & 0.58 & 0.22 & 1.58 & 0.289 \\
\hline CVD & 1.73 & 1.00 & 2.97 & $0.048^{*}$ \\
\hline CKD & 2.45 & 1.45 & 4.14 & $0.001^{*}$ \\
\hline LAMA & 1.00 & 0.59 & 1.70 & 0.994 \\
\hline ICS/LABA & 0.32 & 0.17 & 0.63 & $0.001^{*}$ \\
\hline \multicolumn{5}{|c|}{ History of exacerbations in the previous year } \\
\hline 1 & 1.43 & 0.78 & 2.63 & 0.243 \\
\hline$\geq 2$ & 4.33 & 2.20 & 8.50 & $<0.001^{* *}$ \\
\hline \multicolumn{5}{|l|}{ Malignancy } \\
\hline Lung cancer & 27.24 & 12.16 & 61.04 & $<0.001^{* *}$ \\
\hline Other cancer & 19.39 & 7.85 & 47.87 & $<0.001^{* *}$ \\
\hline \multicolumn{5}{|c|}{ (b) Respiratory-related mortality } \\
\hline Male & 0.83 & 0.34 & 1.98 & 0.667 \\
\hline Age $\geq 65$ & 1.19 & 0.52 & 2.70 & 0.681 \\
\hline Smoking & 0.80 & 0.42 & 1.52 & 0.491 \\
\hline $\mathrm{BMI}>27$ & 0.48 & 0.20 & 1.15 & 0.100 \\
\hline FEV1 $<50 \%$ & 1.82 & 0.97 & 3.41 & 0.060 \\
\hline DM & 0.75 & 0.35 & 1.62 & 0.466 \\
\hline Hyperlipidemia & 0.53 & 0.16 & 1.73 & 0.295 \\
\hline CVD & 1.64 & 0.88 & 3.06 & 0.116 \\
\hline CKD & 1.52 & 0.82 & 2.82 & 0.185 \\
\hline LAMA & 1.11 & 0.61 & 2.03 & 0.739 \\
\hline ICS/LABA & 0.40 & 0.19 & 0.83 & $0.014^{*}$ \\
\hline \multicolumn{5}{|c|}{ History of exacerbations in the previous year } \\
\hline 1 & 2.03 & 1.03 & 4.00 & $0.041^{*}$ \\
\hline$\geq 2$ & 4.61 & 2.14 & 9.93 & $<0.001^{* *}$ \\
\hline \multicolumn{5}{|l|}{ Malignancy } \\
\hline Lung cancer & 35.79 & 15.65 & 81.82 & $<0.001^{* *}$ \\
\hline Other cancer & 11.72 & 4.27 & 32.17 & $<0.001^{* *}$ \\
\hline \multicolumn{5}{|c|}{ (c) Cardiovascular-related mortality } \\
\hline Male & 0.79 & 0.19 & 3.33 & 0.745 \\
\hline Age $\geq 65$ & 3.06 & 0.38 & 24.76 & 0.294 \\
\hline Smoking & 1.11 & 0.39 & 3.14 & 0.849 \\
\hline
\end{tabular}

with the lowest risk of overall death among all treatments [42]. Differently, our reports showed that COPD patients with CKD, CVD, history of frequent exacerbations and underlying malignancies were associated with high risk of all-cause mortality, and those treated with ICS/LABA were associated with better outcome. These results imply that clinicians should not only foucs on the selection of inhaled bronchodilators for COPD, but also target the extra-pulmonary comorbidities as treatable traits to improve outcomes in real-world practice [43].

Our study has several limitations. First, our study population was extracted from only one medical center database, so the results may not be applicable to patients examined at other clinics. Second, not all the prescriptions of inhaled bronchodilators were regulated by guidelines and the data is based on retrospective chart review. Thus, the COPD treatment may not be standardized and the adherence rate of inhalers could not be assessed. Third, the observed association between cardiovascular events in patients with preexisting cardiovascular conditions and the initiation of inhaled bronchodilators does not imply cause and effect. Fourth, we did not include COPD patients with CVD who are not taking inhaled COPD therapies for further clarifying the effects of inhaled bronchodilators on patients with CVD, which is attributed to very few diagnosed COPD patients without receiving any standard inhaled long-acting bronchodilators, even they with CV comorbidity. Fifth, our cohort enrolled relatively higher percentage of nonsmoker COPD patients (49.1\%), 
which could be explained by enrollment of patients with asthma and COPD overlapped (ACO) and our patients had long-term exposure to highest level of fine particulate matter $\left(\mathrm{PM}_{2.5}\right)$ in Taiwan [44]. Sixth, nearly one-fourth of patients $(n=380,24.3 \%)$ had inhaler switching during the follow-up period and were reclassified to different groups after inhaler switch. However, in the real-world data with retrospective nature, we could not avoid the impact of carryover effects without washout periods. Finally, we did not investigate the medications used to treat underlying comorbidities such as DM, hypertension, or hyperlipidemia, or oral drugs for COPD patients.

\section{Conclusions}

The risk of cardiovascular events was associated with COPD patients with preexisting CKD or CVD, and history of frequent exacerbations rather than associated with the use of inhaled bronchodilators. Clinicians should closely monitor COPD patients with preexisting CKD and CVD for adverse cardiovascular events while using inhaled longacting bronchodilators.

\section{Abbreviations}

ACO: Asthma and COPD overlapped; BMI: Body mass index; Ccr: Creatinine clearance rate; CKD: Chronic kidney disease; COPD: Chronic obstructive pulmonary disease; CVD: Cardiovascular diseases; DM: Diabetes mellitus; FEV1: Forced expiratory volume in one second; FVC: Forced vital capacity; ICS: Inhaled corticosteroids; LABA: Long-acting $\beta 2$-agonists; LAMA: Longacting muscarinic antagonists; OR: Odds ratio; PM: Particulate matter

\section{Acknowledgements}

Not applicable

\section{Authors' contributions}

YFC, CHC, CYC, and CJY conceptualized and designed the study. YFC, YCC, CHC and CYC collected the data for the study. YFC, YCC, and CYC analyzed and interpreted the data. YFC and CYC drafted the manuscript. YFC and CYC revised the manuscript critically for important intellectual content. All of the authors have read and approved the manuscript.

\section{Funding}

No funding was obtained for the research.

\section{Availability of data and materials}

The datasets used and/or analysed during the current study are available from the corresponding author on reasonable request.

\section{Ethics approval and consent to participate}

The Research Ethics Committee of National Taiwan University Hospital approved the study protocol and waived informed consent given the retrospective nature of the study and the lack of patient safety concerns.

\section{Consent for publication}

Not applicable

\section{Competing interests}

The authors declare that they have no competing interests.

Received: 11 March 2019 Accepted: 19 November 2019

Published online: 03 December 2019

\section{References}

1. Global Initiative for Chronic Obstructive Lung Disease. Global Strategy for the Diagnosis, Management, and Prevention of Chronic Obstructive
Pulmonary Disease, 2017. https://goldcopd.org/gold-2017-global-strategydiagnosis-management-prevention-copd/.

2. Putcha N, Puhan MA, Hansel NN, Drummond MB, Boyd CM. Impact of COmorbidities on self-rated health in self-reported COPD: an analysis of NHANES 2001-2008. COPD. 2013;10(3):324-32.

3. Vanfleteren LE, Spruit MA, Groenen M, et al. Clusters of comorbidities based on validated objective measurements and systemic inflammation in patients with chronic obstructive pulmonary disease. Am J Respir Crit Care Med. 2013;187(7):728-35.

4. Worth $\mathrm{H}$, Chung KF, Felser JM, et al. Cardio- and cerebrovascular safety of indacaterol vs formoterol, salmeterol,tiotropium and placebo in COPD. Respir Med. 2011;105:571-9.

5. Salpeter SR, Ormiston TM, Salpeter EE. Cardiovascular effects of betaagonists inpatients with asthma and COPD: a meta-analysis. Chest. 2004;125:2309-21.

6. Singh S, Loke YK, Enright $P$, et al. Pro-arrhythmic and pro-ischaemic effects of inhaled anticholinergic medications. Thorax. 2013;68:114-6.

7. Cazzola M, Imperatore F, Salzillo A, et al. Cardiac effects of formoterol and salmeterol in patients suffering from COPD with preexisting cardiac arrhythmias and hypoxemia. Chest. 1998;114:411-5.

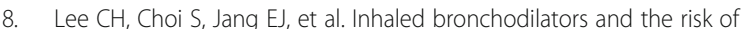
tachyarrhythmias. Int J Cardiol. 2015;190:133-9.

9. Wang MT, Liou JT, Lin CW, et al. Association of Cardiovascular Risk with Inhaled Long-Acting Bronchodilators in patients with chronic obstructive pulmonary disease: a nested case-control study. JAMA Intern Med. 2018; 178(2):229-38.

10. Gershon A, Croxford R, Calzavara A, To T, Stanbrook MB, Upshur R, Stukel TA. Cardiovascular safety of inhaled long-acting bronchodilators in individuals with chronic obstructive pulmonary disease. JAMA Intern Med. 2013;173(13):1175-85

11. Gaddam S, Gunukula SK, Lohr JW, Arora P. Prevalence of chronic kidney disease in patients with chronic obstructive pulmonary disease: a systematic review and meta-analysis. BMC Pulm Med. 2016;16:158.

12. Yoshizawa T, Okada K, Furuichi S, et al. Prevalence of chronic kidney diseases in patients with chronic obstructive pulmonary disease: assessment based on glomerular filtration rate estimated from creatinine and cystatin $C$ levels. Int J Chron Obstruct Pulmon Dis. 2015;10:1283-9.

13. Caillaud D, Le Merre C, Martinat Y, Aguilaniu B, Pavia D. A dose-ranging study of tiotropium delivered via Respimat Soft Mist Inhaler or HandiHaler in COPD patients. Int J Chron Obstruct Pulmon Dis. 2007;2(4):559-65.

14. Türck $D$, Weber $W$, Sigmund $R$, et al. Pharmacokinetics of intravenous, single-dosetiotropium in subjects with differentdegrees of renalimpairment. J Clin Pharmacol. 2004;44(2):163-72.

15. Verhamme KM, van Blijderveen N, Sturkenboom MC. Tiotropium and the risk of death in COPD. N Engl J Med. 2014;370(5):481-2.

16. Wise RA, Anzueto A, Cotton D, et al. Tiotropium Respimat inhaler and the risk of death in COPD. N Engl J Med. 2013;369(16):1491-501.

17. Wedzicha JA, Banerji D, Chapman KR, et al. Indacaterol-Glycopyrronium versus Salmeterol-Fluticasone for COPD. N Engl J Med. 2016;374(23):2222-34.

18. Lipson DA, Barnhart F, Brealey N, et al. Once-daily single-inhaler triple versus dual therapy in patients with COPD. N Engl J Med. 2018;378(18):1671-80.

19. Singh $S$, Loke $Y K$, Furberg CD. Inhaled anticholinergics and risk of major adverse cardiovascular events in patients with chronic obstructive pulmonary disease: a systematic review and meta-analysis. JAMA. 2008; 300:1439-50

20. Singh S, Loke YK, Enright PL, et al. Mortality associated with tiotropium mist inhaler in patients with chronic obstructive pulmonary disease: systematic review and meta-analysis of randomised controlled trials. BMJ. 2011;342:d3215.

21. LaForce C, Derom E, Bothner U, Kloer IM, Trampisch M. Buhl R5. Long-term safety of tiotropium/olodaterol Respimat ${ }^{\oplus}$ in patients with moderate-to-very severe COPD and renal impairment in the $\mathrm{TONADO}^{\circ}$ studies. Int J Chron Obstruct Pulmon Dis. 2018;13:1819-31.

22. Snyder S, Pendergraph B. Detection and evaluation of chronic kidney disease. Am Fam Physician. 2005;72(9):1723-32.

23. Campo G, Pavasini R, Biscaglia S, et al. Overview of the pharmacological challenges facing physicians in the management of patients with concomitant cardiovascular disease and chronic obstructive pulmonary disease. Eur Heart J Cardiovasc Pharmacother. 2015;1(3):205-11.

24. Hillas G, Perlikos F, Tsiligianni I, et al. Managing comorbidities in COPD. Int J Chron Obstruct Pulmon Dis. 2015;10:95-109. 
25. Au DH, Curtis JR, Every NR, et al. Association between inhaled betaagonists and the risk of unstable angina and myocardial infarction. Chest. 2002;121:846-51.

26. Dong YH, Chang CH, Gagne JJ, Hsu CL, Lai MS. Comparative cardiovascular and cerebrovascular safety of inhaled long-acting bronchodilators in patients with chronic obstructive pulmonary disease: a population-based cohort study. Pharmacotherapy. 2016;36(1):26-37.

27. Calverley PM, Anderson JA, Celli B, et al. Salmeterol and fluticasone propionate and survival in chronic obstructive pulmonary disease. N Engl J Med. 2007;356:775-89.

28. Tashkin DP, Celli B, Senn S et al.: a 4-year trial of tiotropium in chronic obstructive pulmonary disease. Expert Opin Pharmacother. 2009;10:719-722.

29. Hohlfeld JM, Vogel-Claussen J, Biller $\mathrm{H}$, et al. Effect of lung deflation with indacaterol plus glycopyrronium on ventricular filling in patients with hyperinflation and COPD (CLAIM): a double-blind, randomised, crossover, placebo-controlled, single-Centre trial. Lancet Respir Med. 2018;6(5):368-78.

30. Aljaafareh A, Valle JR, Lin YL, Kuo YF, Sharma G. Risk of cardiovascular events after initiation of long-acting bronchodilators in patients with chronic obstructive lung disease: a population-based study. SAGE Open Med. 2016; 4:2050312116671337 eCollection 2016.

31. Gaddam S, Gunukula SK, Lohr JW, Arora P. Prevalence of chronic kidney disease in patients with chronic obstructive pulmonary disease: a systematic review and meta-analysis. BMC Pulm Med. 2016;16(1):158.

32. Chen CY, Liao KM. Chronic Obstructive Pulmonary Disease is associated with risk of Chronic Kidney Disease: A Nationwide Case-Cohort Study. Sci Rep. 2016;6:25855.

33. Mapel DW, Marton JP. Prevalence of renal and hepatobiliary disease, laboratory abnormalities, and potentially toxic medication exposures among persons with COPD. Int J Chron Obstruct Pulmon Dis. 2013;8:127-34.

34. Levey AS, de Jong PE, Coresh J, et al. The definition, classification, and prognosis of chronic kidney disease: a KDIGO controversies conference report. Kidney Int. 2011;80(1):17-28.

35. Di Lullo L, House A, Gorini A, et al. Chronic kidney disease and cardiovascular complications. Heart Fail Rev. 2015;20(3):259-72.

36. Kunz C, Luedtke D, Unseld A, et al. Pharmacokinetics and safety of olodaterol administered with the Respimat soft mist inhaler in subjects with impaired hepatic or renal function. Int J Chron Obstruct Pulmon Dis. 2016;11:585-95.

37. Navaneethan SD, Schold JD, Huang H, et al. Mortality outcomes of patients with chronic kidney disease and chronic obstructive pulmonary disease. Am J Nephrol. 2016;43(1):39-46.

38. van Gestel YR, Chonchol M, Hoeks SE, et al. Association between chronic obstructive pulmonary disease and chronic kidney disease in vascular surgery patients. Nephrol Dial Transplant. 2009;24(9):2763-7.

39. Lai CC, Wu CH, Wang YH, Wang CY, Wu VC, Chen L. The association between COPD and outcomes of patients with advanced chronic kidney disease. Int J Chron Obstruct Pulmon Dis. 2018;13:2899-905.

40. Gershon A, Croxford R, To T, et al. Comparison of inhaled long-acting $\beta$-agonist and anticholinergic effectiveness in older patients with chronic obstructive pulmonary disease: a cohort study. Ann Intern Med. 2011;154:583-92.

41. Vogelmeier C, Hederer B, Glaab T, et al. Tiotropium versus salmeterol for the prevention of exacerbations of COPD. N Engl J Med. 2011;364:1093-103.

42. Dong YH, Lin HH, Shau WY, Wu YC, Chang CH, Lai MS. Comparative safety of inhaled medications in patients with chronic obstructive pulmonary disease: systematic review and mixed treatment comparison meta-analysis of randomised controlled trials. Thorax. 2013;68(1):48-56.

43. Agusti A, Bel E, Thomas M, et al. Treatable traits: toward precision medicine of chronic airway diseases. Eur Respir J. 2016;47(2):410-9.

44. Lo WC, Shie RH, Chan CC, Lin HH. Burden of disease attributable to ambient fine particulate matter exposure in Taiwan. J Formos Med Assoc. 2017;116:32-40.

\section{Publisher's Note}

Springer Nature remains neutral with regard to jurisdictional claims in published maps and institutional affiliations.

\section{Ready to submit your research? Choose BMC and benefit from:}

- fast, convenient online submission

- thorough peer review by experienced researchers in your field

- rapid publication on acceptance

- support for research data, including large and complex data types

- gold Open Access which fosters wider collaboration and increased citations

- maximum visibility for your research: over $100 \mathrm{M}$ website views per year

At BMC, research is always in progress.

Learn more biomedcentral.com/submissions 